\title{
A TEORIA DE AUSUBEL E A SELEÇÃO DE CONTEÚDOS DE ENSINO
}

Helena Faria de Barros*

Aceita-se, em Educação, que atividades docentes trazem o matiz da teoria que o professor sustenta até, muitas vezes, de modo implícito. Conceitos básicos direcionam o trabalho docente, conferindo-lhe feição. Assim, conceitos como os de educação, escola, conhecimento, aprendizagem e ensino constituem alicerces essenciais,visto que práticas pedagógicas se explicitam, diferentemente, e com efeitos diversos, segundo as características que tenham assumido, enquanto conceito.

Por outro lado, aceita-se, igualmente, que educar é práxis tal como a concebe Aristóteles, isto é, uma "ação informada" em que a reflexão sobre a natureza e conseqüências da própria ação provoca mudanças, submetendo à revisão permanente tanto a própria ação como os conhecimentos que a fundamentam e desencadeiam. Para aquele filósofo, essa característica das disciplinas "práxis" as diferenciam das ciências teóricas (que se esgotam na busca da verdade pela contemplação e em ter por "téleo" o conhecimento em si) e das ciências práticas ou produtivas

* Doutora em Educação - UNESP, Presidente Prudente - SP. Livre Docente - Universidade Federal de Santa Maria - RS. Coordenadora do Mestrado em Educação - UCDB - Campo Grande-MS. 
(por consistirem numa "ação em curso", "ação em processo", qualificada pelo fato de uma imagem-força dirigir o ato de produção através de um modelo acabado, sempre igual, e pelo fato dessa ação se evidenciar em destrezas e artesanias como um "saber fazer" e "fazer bem" alguma coisa).

As idéias, acima expostas, foram perseguidas como fundamentais na disciplina Didática do Ensino Superior, no Curso de Mestrado em Educação que propunha como um dos objetivos a reflexão sobre a atuação do próprio docente para aperfeiçoá-la. Assim, o desenvolvimento dessa disciplina pôde proporcionar aos mestrandos-professores, momentos de discussão e reflexão sobre a própria atuação em aula e deu origem a execução de trabalhos práticos, referentes aos temas estudados, como alternativa de solução de problemas didático-pedagógicos, vividos no cotidiano escolar. A maioria desses trabalhos foi relativa a currículo e à elaboração de programas de disciplinas diversas. Alguns deles aparecem relatados aqui, nesta mesma publicação.

No intuito de oferecer condições de contexto para melhor compreensão do conteúdo e do sentido destes trabalhos publicados, se retoma, a seguir, alguns aspectos da teoria de Ausubel que, discutidos naquela disciplina do Mestrado, inspiraram as citadas vivências e são indicativos de mudanças na "práxis" dos que a sustentaram. Não se trata, então, de ato de repetição pura e simples daquela teoria, mas representa um esforço de pôr em destaque algumas das idéias que serviram para encaminhar os ditos trabalhos práticos que lhes deram sentido. A apresentação dessas idéias constitui, também, a síntese que se conseguiu 
elaborar sobre a teoria referida.

Na unidade "Seleção e Organização de Conteúdos de Ensino"do programa estudado, a idéia básica extraída da teoria ausubeliana foi: o ato de conhecimento (na aprendizagem escolar) pode ser analisado do ponto de vista das relações que se estabelecem entre a estrutura cognitiva psicológica de quem aprende e a estrutura cognitiva lógica da matéria de ensino (disciplinas), ou seja, das relações entre os corpos de conhecimentos organizados, que representam a sabedoria coletiva, conquistada e registrada em áreas específicas de investigação internalizada e os alunos, individualmente, possuidores de graus variáveis de amadurecimento cognitivo, de atitudes e de habilidades para com aqueles conhecimentos.

Há diferença entre a organização formal do conteúdo das matérias de ensino que se constitui de enunciados, reconhecidamente, válidos e aceitos de modo generalizado; e a representação organizada e internalizada (assimilada) deste mesmo conhecimento, na estrutura da memória de indivíduos particulares.

Pode-se dizer que essas estruturas de conhecimento, lógica e psicológica, são semelhantes em alguns aspectos e diferentes em relação a três atributos principais: significado, processo de organização e encadeamento, ordem e disposição dos elementos componentes.

Quanto ao atributo significado a distinção se estabelece porque o conteúdo de uma disciplina pode possuir significado lógico ou potencial, e isto acontence quando este conteúdo se apresenta integrado por relações virtuais, 
possíveis de serem estabelecidas, de modo substantivo, com uma estrutura cognitiva humana, hipotética, portadora de fundamentos conceituais e de maturidade cognitiva. "Os conceitos existem no mundo enquanto realidadesestímulo. Isso é o que quero dizer com a expressão significado lógico" (Ausubel, 1973).

Esse critério de significado lógico potencial se aplica, principalmente, ao material de aprendizagem. Se ele apresenta características de não arbitrariedade, de coerência, de clareza e de possibilidade de relacionamento, por definição, pode ser conectado à estrutura cognitiva, hipotética, referida. Material potencialmente significativo é aquele "suscetível de dar lugar à construção de significados" (Coll, 1994).

A possibilidade de incorporação não arbitrária de conceitos significativos, em uma estrutura cognitiva individual particular, torna possível transformar o significado lógico em psicológico e depende do esforço deliberado do aprendiz em estabelecer o relacionamento da nova informação com os conceitos relevantes pré-existentes e das possibilidades que o conteúdo conceitual específico possa oferecer. Um aluno não aprende o significado lógico da matéria, mas o significado que essa lógica possa ter para ele. O significado psicológico é sempre idiossincrásico, é elaborado pelas pessoas individualmente e não exclui a possibilidade dos significados sociais, coletivos e compartilhados.

A aprendizagem consiste, assim, no processo de aquisição/elaboração de significados, a partir dos significados potenciais do material de aprendizagem e consiste 
em que esses significados adquiram maior disponibilidade para o sujeito que aprende. A incorporação (inclusão) hierárquica de material novo à estrutura cognitiva existente no sujeito constitui o fundamental, no surgimento de um novo significado. A aprendizagem significativa é um processo de assimilação (inclusão) em que o contéudo do novo material adquire sentido para o sujeito, pelo e no processo mesmo de incorporação que sofre.

Pode-se dizer, em síntese, que a interdependência e a diferença entre a estrutura lógica e psicológica do conhecimento é a seguinte: de um lado a estrutura psicológica do conhecimento é uma elaboração idiossincrásica do significado lógico; por outro lado, a estrutura lógica do conhecimento é uma organização, tematicamente, sistematizada da estrutura psicológica do conhecimento, tal como a fazem os eruditos maduros de uma disciplina particular.

As estruturas lógica e psicológica do conhecimento diferem também quanto aos processos de organização específicos de ambas, além do elemento significado. Do ponto de vista do processo, as leis que se aplicam à organização psicológica do conhecimento são as normas da aprendizagem significativa e da retenção ativa (da temática, do conteúdo de aprendizagem), enquanto que as que governam a organização lógica do conhecimento procedem do formal, isto é, da lógica da classificação, da inclusão. Esses dois conjuntos de leis se sobrepõem à medida em que aprendizagem significativa de novos conceitos deve se ajustar aos princípios da classificação lógica, isto é, à proporção que tal aprendizagem se cons- 
titui num processo de inclusão dos novos aos conceitos relevantes, já existentes psicologicamente, e possuidores de nível elevado de generalidade e de inclusividade.

O sistema nervoso humano, como mecanismo de processamento e acoplagem de dados, é de tal natureza que os conceitos novos só podem ser aprendidos e retidos, significativamente, à medida em que existam disponíveis, na estrutura cognitiva (psicológica), conceitos mais inclusivos e relevantes que possam desempenhar a função de inclusão, de modo a proporcionar uma ancoragem conceitual.

Desta maneira, não só ambos os processos organizatórios se atêm à lógica da classificação, como empregam também os mesmos princípios: estruturar o conhecimento em função de elementos unificadores que apresentem a máxima generalidade e poder explicativo, além de relacionar e integrar, o mais amplamente possível, o campo da disciplina.

Tem-se, então, que o princípio de inclusão proporciona a chave para a compreensão dos processos que subjazem ao crescimento (acúmulo) psicológico e à organização lógica do conhecimento.

Um último aspecto de diferenciação entre a estrutura lógica e a psicológica do conhecimento se refere ao encadeamento, ordem e disposição dos elementos componentes dessas estruturas. A organização psicológica (isto é, a aprendizagem significativa e a retenção ativa) implica numa estruturação hierárquica dos conceitos que se diferenciam, progressivamente, em função do grau de 
generalidade presente neles. Essa estruturação hierárquica, o aprendiz, dinâmica e gradativamente, vai estabelecendo para e em si. A partir dos conceitos mais gerais e inclusivos, a estrutura cognitiva psicológica sofre e elabora uma diferenciação progressiva dos conceitos na medida da subsunção dos novos materiais de aprendizagem pelos conceitos mais relevantes e mais inclusivos existentes. $\mathrm{O}$ mesmo processo se dá (se repete) na ordem lógica do material de aprendizagem.

Assim, a inclusão responde pela "cumulação" na (e da) estrutura psicológica do conhecimento ao realizar a aquisição de novos significados, e sua retenção.

"O residuo cumulativo daquilo que é aprendido, fixado e esquecido (a estrutura psicológica do conhecimento ou a estrutura cognitiva como um todo) submete-se ao princípio organizador da diferenciação progressiva. Conseqüentemente, se a assimilação é operativa na estocagem de idéias significativas, então seria bastante compreensivel por que uma organização mental individual do conteúdo de uma disciplina particular exemplifica uma pirâmide ordenada hierarquicamente" (Ausubel et. alii, 1968:107).

No processo de inclusão está a razão, pela qual a organização do conteúdo de uma disciplina, elaborada pelo sujeito em sua própria mente, seja uma estrutura hierárquica em que os conceitos mais inclusivos ocupam o ápice e envolvem subconceitos e dados fáticos, progressivamente, menos inclusivos e de grau de dife- 
renciação, cada vez, mais alto.

Por outro lado, a estruturação lógica do conhecimento utiliza, também, conceitos gerais e inclusivos como elementos organizadores, mas não consegue conexão e homogeneização temática (que lhe são necessários e essenciais), unicamente, pela diferenciação progressiva da matéria, pois necessita do significado.

Do ponto de vista psicológico, um aprendiz se aproxima da estruturação lógica do conhecimento nas etapas finais da elaboração da matéria, depois que o "individuo desenvolve capacidades cognitivas maduras, conhecimento dextro e especializado de uma matéria" (Ausubel, 1973).

Só então a estrutura psicológica do conheci-mento dessa disciplina corresponde (de modo pouco menos sistematizado) à sua estrutura lógica. Nesse estágio é que o indivíduo pode reorganizar, facilmente, sua estrutura psicológica em termos de ordenamento das relações entre fatos, conceitos e proposições componentes, de maneira mais homogênea e sistemática, do ponto de vista temático. O paralelismo entre a estrutura lógica e psicológica do conhecimento não existe durante os primeiros estágios do desenvolvimento intelectual. Pode-se dizer que a estrutura lógica do conhecimento depende necessariamente dos processos cognitivos humanos (isto é, da estrutura psicológica), sendo mesmo produto deles. Só os seres humanos com capacidade cognitiva madura e estrutura psicológica, grandemente elaborada, numa disciplina, podem estruturar o campo de conhecimento de maneira satisfatória quanto à lógica.

Como reforço convém repetir-se que, entre a es- 
trutura lógica e a psicológica do conhecimento, prevalece o seguinte grau de interdependência: por um lado, a estrutura psicológica deriva de um conteúdo da matéria abstraído da estrutura lógica do conhecimento e o significado psicológico é uma elaboração idiossincrásica do significado lógico; por outro lado, a estrutura lógica do conhecimento é uma organização temática, sistematizada da estrutura psicológica do conhecimento, tal como a fazem os eruditos maduros de uma disciplina particular. Ambas acontecem por um processo de diferenciação progressiva em que as idéias mais específicas sofrem o processo de subsunção pelas idéias mais gerais.

Destacam-se, ainda, a seguir, outros aspectos da Teoria de Ausubel, implicados nos trabalhos realizados pelos mestrandos, que seriam, na realidade, um outro enfoque dos já vistos até aqui, a partir de outro ângulo.

- A aprendizagem pode ser significativa ou mecânica e ambas podem acontecer por recepção verbal ou por descoberta (aprendizagem investigativa). Esses tipos, possíveis, formam dois "continua" que se interpõem de modo que as duas seqüências permitam a passagem da descoberta à recepção verbal ou vice-versa, e da aprendizagem mecânica à aprendizagem significativa ou vice-versa, numa variação de possibilidades.

- A aprendizagem significativa dá-se à medida que o material potencialmente significativo entra no campo cognitivo e interatua nele, sendo, apropriadamente, incluído no sistema conceitual (estrutura psicológica) existente, adquirindo significado fenomenológico que é sempre idiossincrásico. Ela é, portanto, um processo cognitivo em 
que a nova informação (ou conceito, ou proposição) se incorpora de modo substantivo, não artificial e não arbitrário, aos conceitos já existentes na estrutura cognitiva do aprendiz, sempre na dependência do nível de desenvolvimento atingido por esses conceitos quanto à generalidade e à inclusividade e das atitudes intelectuais favoráveis de quem aprende e do material de aprendizagem.Como diz Coll, (1994:48) comentando Ausubel,

" $A$ aprendizagem significativa é o processo de construção de significados. $O$ aluno aprende um conteúdo qualquer - um conceito, uma explicação de um fenômeno físico ou social, um procedimento para resolver determinados tipos de problemas, uma norma de comportamento, um valor a respeito de algo, etc. - quando é capaz de atribuir-lhe um significado".

Neste tipo de aprendizagem a nova informação se relaciona (interage) com aspectos relevantes, préexistentes da estrutura cognitiva psicológica e tanto a nova informação como a própria estrutura pré-existente são modificadas no processo.

"O resultado dessa interação, que ocorre entre o novo material e a estrutura cognitiva existente, é a assimilação dos significados velhos e novos, dando origem a uma estrutura mais altamente diferenciada" (Ausubel 1978:57).

O termo "assimilação" é empregado nesta teoria em sentido restrito, referindo-se à ligação (inclusão) do novo 
significado com a idéia básica, com a finalidade de armazenagem e posterior processo de recordação.

- Quanto à aprendizagem mecânica Ausubel (1968:41) explica que

"tarefas mecânicas, naturalmente, não são dominadas em um vácuo cognitivo. Elas são relacionadas à estrutura cognitiva psicológica mas apenas de modo arbitrário, verbatim, que não resulta na aquisição de quais significados" ou, então, "aquilo que se aprende mecanicamente não pode servir como inclusor, pois não possui nenhum conteúdo mental claro que seja seu ponto de referência na estrutura cognitiva. Se trata meramente de uma associação arbitrária, a qual, por definição, não tem significado algum e, portanto, não pode ser produto da inclusão".

- Ambas, a aprendizagem mecânica ou a significativa, acontecem tanto na aprendizagem por descoberta como na recepção verbal. Nesta última, a essência do que deve ser aprendido (o material de aprendizagem, o novo conceito) é oferecida ou dada ao aprendiz, geralmente, sob a forma verbal e não requer uma investigação autônoma por parte do aluno, nem uma reorganização dos conceitos existentes na estrutura cognitiva psicológica em função do enfrentamento de uma situação problema. Quando, então, a substância do que deve ser aprendido (o novo significado) implica certa manipulação independente por parte do aluno tem-se o exemplo da aprendizagem por descoberta, que pode ser vista como aprendizagem de um tipo especial. A apren- 
dizagem receptiva verbal consiste e exige sempre a lógica da classificação, a inclusão, enquanto que a aprendizagem por descoberta não a supõe e nem a exige, precedendo sempre a incorporação do conceito descoberto à estrutura cognitiva do aprendiz. Dito de outro modo, na investigação existe um primeiro momento, o da aprendizagem por descoberta, que não é a inclusão e, a seguir, um segundo momento subseqüente, o da incorporação dos conceitos recentemente descobertos à estrutura cognitiva (a inclusão). A descoberta não implica a inclusão, mas se alguém descobre conceitos e não os incorpora (à estrutura cognitiva psicológica), fixando-os, todo o essencial do descobrimento ou pelo menos grande parte dele se perderá. Uma vez completada a fase de descobrimento da aprendizagem, a teoria inclusiva se torna implícita no processo incorporativo.

- A aquisição de conhecimento em qualquer cultura é primordialmente uma manifestação da aprendizagem receptiva, ou seja, o conteúdo principal daquilo que vai ser aprendido é, geralmente, apresentado ao aluno sob forma mais ou menos final, acabada.

"Exige-se do aluno simplesmente compreender o assunto e incorporá-lo à sua estrutura cognitiva de modo que fique disponível, ou para ser relacionado a uma nova informação, ou para solução de problema em alguma situação futura" (Ausubel, 1978:98).

A exposição oral, bem feita, onde o material de aprendizagem é apresentado com organização, ordem, disposição e seqüência, de modo que o torne, potencialmente, significativo é condição essencial para a aprendizagem 
significativa. Confirma o autor que o material de aprendizagem (conceitos, proposições) é com freqüência apresentado aos alunos de tal forma que só pode ser aprendido mecanicamente (não potencialmente significativo).

- O processo de ensino é explicado como a tentativa de influir deliberadamente sobre a estrutura cognitiva (psicológica) a fim de maximizar a aprendizagem significativa e a retenção ativa, principalmente, apresentando o material de aprendizagem de modo a ser, potencialmente, significativo.

"A teoria da assimilação", diz Ausubel, "tem valor explicativo tanto para o fenômeno da memorização quanto para o fenômeno da aprendizagem, porque tanto é responsável pela forma como o conhecimento é organizado na estrutura cognitiva como pela sua retenção." (Ausubel, 1978:107).

- No processo da aprendizagem significativa acontecem a elaboração de significados (a partir de significados potenciais que se apresentam no material de aprendizagem) e a conquista de maior disponibilidade para esses significados. Essa disponibilidade diz respeito à reprodução dos novos significados adquiridos.

A retenção consiste na manutenção desta disponibilidade, enquanto que o esquecimento, na diminuição dela. As idéias recentemente adquiridas, que estão relacionadas (inclusas) ao "esteio de idéias" à idéia mais geral, tendem, gradual e espontaneamente, a se tornar indissociáveis de suas "idéias básicas", isto é, tornarem-se esquecidas. É um 
processo econômico, natural de redução da memória. É a influência erosiva da tendência reducionista geral da organização cognitiva. É mais econômico e menos difícil reter apenas conceito e proposições básicos, mais estáveis, claros e estabelecidos do que evocar as novas idéias específicas. O significado das novas informações é assimilado ou reduzido, no decorrer de um espaço de tempo, aos significados mais estáveis das idéias gerais. Há um caminho a percorrer, desde a forte dissociação inicial entre as novas idéias já estabelecidas, até a fraca dissociação das primeiras como entidades autônomas.

É, portanto, a mesma relação não arbitrária estabelecida entre a idéia nova e a idéia relevante pré-existente, que é necessária e fundamental à elaboração do significado que explica, também, um "aperfeiçoamento" da memorização através do processo de sustentar o significado na mesma base de apoio.

Desta maneira, o esquecimento é considerado uma continuação ou uma fase temporal, posterior do mesmo processo assimilativo, subjacente à disponibilidade de idéias, recentemente, adquiridas.

As implicações desta teoria para o ensino são:

1. A estrutura psicológica do aluno é a variável independente mais importante, que influi sobre a capacidade de adquirir conhecimentos novos pelo aprendiz: "o fator isolado mais importante que influencia a aprendizagem é aquilo que o aprendiz já conhece. Descubra o que ele sabe e baseie nisso seus ensinamentos" (Ausubel, 1968:41). 
2. Pode-se exercer um controle mais efetivo sobre a organização, exatidão, clareza, duração mnemônica de um dado corpo de conhecimento, isto é, o ensino pode acontecer e consiste principalmente no esforço de proporcionar ao aprendiz material e atividades, potencialmente, significativos: a organização, clareza, estabilidade do material de ensino são fundamentais à aprendizagem significativa.

3. Na organização do material de ensino, o princípio da diferenciação progressiva deve ser obedecido. Há que se valer de princípios programáticos convenientes para ordenar a seqüência da matéria, construindo sua lógica interna e sua organização.

Devem-se introduzir, na seqüenciação do conteúdo e oferecer à aprendizagem dos alunos, aqueles conceitos e preposições unificadores da disciplina ensinada e que tenham, também, o mais amplo poder explicativo. Só assim, poder-se-á influir e facilitar a formação progressiva da estrutura cognitiva psicológica pelo aluno, de modo hierárquico em que, igualmente, conceitos mais amplos e inclusivos sejam formados de início, depois os secundários e a seguir os muito específicos e detalhados.

4. A aprendizagem significativa deve apresentar a característica "consolidação" e, para tanto, antes de introduzir novos materiais, devem-se assegurar uma facilidade e um êxito contínuos na aprendizagem organizada de modo seqüencial. O passo precedente deve ser sempre claro, estável e bem organizado e, em conseqüência, nunca se deve introduzir novo material em seqüência, antes do domínio dos passos precedentes. 
A estabilidade e a clareza da estrutura cognitiva psicológica são importantes tanto para a profundidade da ancoragem, como para seus efeitos sobre a memória.

Para esta "consolidação" é importante que, na organização do material de aprendizagem, se observe também o princípio da "reconciliação integrativa", que consiste no espírito e no enfoque contrário a compartimentar e isolar os conceitos (comum ouvir que se deve ensinar perímetro sem falar em área para evitar que o aluno estabeleça confusão entre ambas). Os temas e os conceitos devem ser superpostos de maneira auto-inclusivas, de modo que todas as referências cruzadas possam ser percebidas. Esforços sérios devem ser realizados com a finalidade explícita de explorar as relações com outros conceitos, destacar semelhanças e diferenças significativas e conciliar inconsistências reais e aparentes.

Convém insistir que o uso adequado de conceitos relevantes, previamente aprendidos, como base (como esteio de idéias, como matriz ideacional) para incluir e incorporar nova informação é essencial na aprendizagem significativa, tanto quanto o tornarem explícitas as diferenças significativas entre aspectos, aparentemente similares e a percepção de conceitos como idênticos ou diferentes.

Em alguns casos de aprendizagem significativa e de retenção ativa, a dificuldade principal não é a discriminação, mas a aparente contradição entre conceitos estabelecidos na estrutura cognitiva, psicológica e as novas proposições do material de aprendizagem. Nestas condições o aluno pode, erradamente, desistir das novas proposições como válidas, pode tratar de compartimentá-las como entidades 
isoladas e separadas do conhecimento previamente aprendido, ou tentar uma conciliação integrativa sob um inclusor mais amplo.

A estabilidade e a clareza da estrutura psicológica do conhecimento existente são importantes tanto para a profundidade da ancoragem (da inclusão), que proporciona às novas aprendizagens, como por seus efeitos sobre o poder de discriminação destas novas aprendizagens. A reconciliação integrativa torna possível a efetivação de ambos os efeitos.

Quando toda uma cadeia de conceitos é apresentada, inicial e simultaneamente, ao aluno, em lugar de ser apresentada, sucessivamente, a aquisição do conceito é facilitada de modo acentuado. Supõe-se que esta ação indica a possibilidade de se agrupar mais, intimamente, os atributos essenciais de um conceito durante o processo de abstração, facilita o surgimento ou formação do

"esteio de idéias gerais, inclusoras e relevantes, a matriz ideacional capaz de proceder inclusões subseqüentes permite a reconciliação integrativa e a consolidação tornando os conceitos claros e estáveis" (Ausubel, 1973).

5. Quando não existe nenhum conceito mais geral e inclusivo capaz de permitir a inclusão do novo conceito, Ausubel aconselha, no ensino, o emprego de organizadores prévios, que consiste num material introdutório (um fato, uma notícia, um evento, uma poesia e nunca um sinótico ou resumo) para proporcionar inclusões próximas e releventes, que permitam uma ancoragem conceitual em termos já tão familiares ao aluno. Esses organizadores podem ser de natureza expositiva e/ou comparativa e aumentam o poder 


\section{REFERÊNCIAS BIBLIOGRÁFICAS}

AUSUBEL, D. Novak, I.D. e HANESIAN, H. Psicologia educacional. Rio de Janeiro : Interamericana,1978.

AUSUBEL, D. Algunos aspectos psicológicos de la estructura del conocimiento. In: ELAM, Stanley. La educacion y la estructura del conocimiento. Buenos Aires : El Ateneo, 1973.

COLL, Cesar S. Aprendizagem escolar e construção do conhecimento. Porto Alegre : Artes Médicas, 1994. 